The menorrhagia was profuse, and the patient's strength sinking very fast, cold applications, acids, kino, lead, were all tried in vain to arrest the flooding. The uterus was attacked with pains like those of parturition, and ergot of rye was used as a last resource, in five grain doses every fourth hour, with success, the menorrhagia ceasing instantly. As pressure relieved the pain, a bandage of large size was applied around the abdomen. My friend was then led to use the emplastrum belladonnæ, from seeing it recommended strongly in Dr. Churchill's work; it had in this, as in the other case, an immediate effect : the patient is now (two years since) quite well, and travelling. I hope this last case will be useful in a double point of view, as showing the beneficial effects of the ergot in menorrhagia, when other remedies have failed, and as proving that treatment directed by the supposition of the inflammatory character of the disease is useless, and even hurtful; the relief af forded to the patient by the use of the belladonna, should also be borne in mind. I am, Sir, a constant reader of your Journal.

MEdicus.

\section{DEATH AND AUTOPSY OF GENERAL CORDOVA.}

\section{To the Editor of THE LANCET.}

SIR:-Should the following account of the post-mortem examination of General Cordova, an officer whose name has of late years been much before the public, be deemed worthy of a place in your valuable Periodical, it is much at your service. I have the honour to be, Sir, your obedient servant,

\section{T. Cunningham.}

Her Majesty's ship Donegal,

Lisbon, May 4, 1840.

General Corỏora, it would appear, suffered most severely from what his medical men called dyspepsia for the last eight years, which rendered his life very miserable, and reduced him to a mere skeleton. Abont three weeks since, when on the eve of departure for England, he was seized with symptoms resembling enteritis, which were treated actively enough by Dr. B., a celebrated physician here; but, from his extreme debility, and his apathy as regards life (in fact, he wished to die), he gradually sank and expired, after much suffering, on the morning of the 29 th ultimo, in, I believe, his 42 nd year.

\section{Autopsy Twenty-four Hours after Death.}

The external appearance presented an extreme degree of emaciation, with sores in the sacral region, which were nearly in a state of gangrene, and were surronnded by a livid appearance, extending along the back.

On laying open the thorax and the abdo. men, which was done (Portuguese fashion) by making an oblong circular incision from the anterior and superior spinous process of the ilium, across the pubes, and then upwards to the clavicle, dividing the ribs at about their centre (a tedious process, but an excellent one for exposing the thoracic and abdominal organs); the peritoneum was found highly inflamed, and agglutinated to the intestines throughout, forming five dis" tinct cavities, which did not communicate with each other, and contained upwards of a gallon of sero-purulent fluid, of a whitish. chocolate colour, and very foetid. There were also large flakes of false membrane, particularly on the under surface of the diaphragm. The liver was very large, but normal. The mesenteric glands were in a state of suppuration. The stomach was empty, and thicker than natural, with an inflammatory blush extending around the cardiac orifice. The pyloric orifice was surrounded by a cancerous tumour, extending for some distance into the duodenum, which accounted very satisfactorily for the long and truly distressing dyspeptic symp. toms. The mucous membrane of theintestines was not so much inflamed as was expected. The spleen was very small, and of a whitish hue. The pancreas, kidneys, and bladder were healthy. The oesophagus, at its lower third, was coated with a firm black pig. mentary layer, which resisted the scalpel and washing. The thoracic viscera were normal. The head was opened, to remove the brain for the purpose of embalming; it wns large, very firm, and healthy.

\section{CASTRATION FOR VARICOCELE,}

\section{To the Editor of THE LANCET,}

SIR:-A case, headed "Castration for Varicocele," occurs in your current Num. ber, April 18th, to which is appended the signature of Mr. Moses Thompson, one of the medical practitioners of this place; and as it is very generally known here that the patient was in the first instance under my care, I trust that your usual impartiality and sense of justice, will permit me to de. tail the practice I considered myself bound to adopt.

I first saw the patient three years ago; the disease having been closely watched during that interval, it was found to remain nearly stationary. At that period (and the same description will answer up to the date of its removal) there was a slight varicose enlargement of the upper portion of the epididymis of the left side, some pain, but not of such exhausting character as materially 